\title{
Models and muddles
}

\section{Some philosophical observations}

\author{
J. W. Hedgpet'H \\ Santa Rosa, California, USA
}

\begin{abstract}
The first model in marine ecology was that of the biocoenosis by Moebius (1883), conceived as a self-contained box limited by a finite food resource. This box was almost immediately broken bown by Dean (1893) and demonstrated to be a bit of a muddle, but the concept and the general term has persisted. Today, the construction of elaborate diagrams and mystico-mathematical representations of assumed relationships powered by selected values is a favorite pastime of many ecologists and "environmental engineers". When taken with a grain of salt (preferably benzoate of soda), such models may stimulate further thought. Fisheries biologists have had some success with single species or paucispecific models, but complex models require simplification and selection of data unrepresentative of nature. A model which is simply an elaborate mathematical summary of a textbook does not tell us much more than we allready know, and its formulation involves a questionable diversion of funds.
\end{abstract}

After a manner of speaking, this discussion is a sequel to my previous comments on the impact of impact studies (Hedgpeth, 1972), given when I was last at an International Helgoland Symposium, in 1972. Obviously, I was unduly optimistic, and I had forgotten that old Welsh proverb which should govern the advent of new developments in science - or any other human activity: "Nid y bore y mae cammol diwrnod teg" (Never praise a fine day in the morning). None of us, perhaps, anticipated how rapidly the access to computers would encourage the burgeoning subscience, or intellectual activity, of modelling.

There is of course no inherent evil in attempting to simplify what we know or suspect of nature so that we can handle the almost infinite variations of events in the natural world, and perhaps to arrive at some modest hope of prediction. Unfortunately, however, many, and for the most part those not directly concerned with modelling activity, see in equations facts rather than ideas. Then there are those who are capable of designing models to suit the needs of whoever may be putting up the money.

A rigorous course in the history of science and an introduction to mathematics as a dream world might be a good idea for all of us as we are confronted with this growing forest - or bamboo thicket - of models. For most of us, alas, the time for leisurely philosophical contemplation is past - or not yet attained, yet we must never- 
theless retain some judicious skepticism before we are lost in the dense thickets of this suddenly proliferating literature. Today, we have entire symposia, volumes and a journal, dedicated to the whys and wherefores of models in the marine environment. The ease with which the computer generates numbers has produced this unanticipated growth.

Models take many forms. Abstract or primitive art is expression in the form of a model; often, such expressions are pleasing even to sophisticates (or perhaps especially so) because of the evocation of reality. All of us use such abstractions on the blackboard, and often such casual diagrams are the genesis of more serious and elaborate abstractions, although blackboard art itself is one of the most evanescent of art forms, like conversation. It is designed to be erased and lost.

In the case of art, the model is the real thing, usually thought of as a well-shaped female, and what is modelled from her curves is the work of art. Much modern art is an obvious effort to depart as far as possible from the reality of the model to some abstraction or elliptical evocation of the mysterious processes within the mind of the artist. Science, however, relies upon models that are abstractions to begin with, in an attempt to understand the "real world" of nature. Philosophically, there may not be much difference in the approaches of artist and scientist. After all, the meteorologist Sir Napier Shaw characterized a model as a fantasy when he said, "Every theory in the course of nature is necessarily based on some process of simplification and is to some extent therefore a fairy tale." Obviously, we need to remind ourselves often of this remark; despite its prominent place at the head of my own summary of our state of ecological knowledge two decades ago (Hedgpeth, 1957), it still seems to have eluded many possible readers.

A model may be a picture, a diagram, an abstract concept requiring vague words for expression, or an equation. In recent years, within the last decade and a half for the most part, elaborate equations, expressions of theories and ideas of what might possibly be happening, have become one of the principal entrees in the menu of ecology. Sociological matters, including religion, are not immune, as Figure 1 demonstrates (Odum, 1971). The idea that the progression of events in nature might be reproduced by an almost infinite series of differential equations has attracted not only ecologists, but mathematicians, physicists, and engineers, with varying results. The development of computers and of easy access to them by those who have the wherewithal from their granting fathers has resulted in a plethora of equations and numbers, and a promise of more to come. If one approaches these efforts through the gray or soft paper literature, the progress reports demanded by government agencies, and the various preliminary, too-often unedited versions of what may never become formally published papers subject to the critical eye of a possibly unconvinced if not unfriendly editor, one gets the impression that here is "the real world": these are the numbers we must believe in.

The danger here is that these numbers may indeed be believed and applied to policy governing sewage disposal, nuclear waste treatment, or whatever, and then, when the numbers do not agree, result in possibly unnecessary or dangerous changes in rules. Biologists, by nature aware of variation, boundary conditions, exponential increases in numbers, and accumulation of natural populations and the subtly variable 


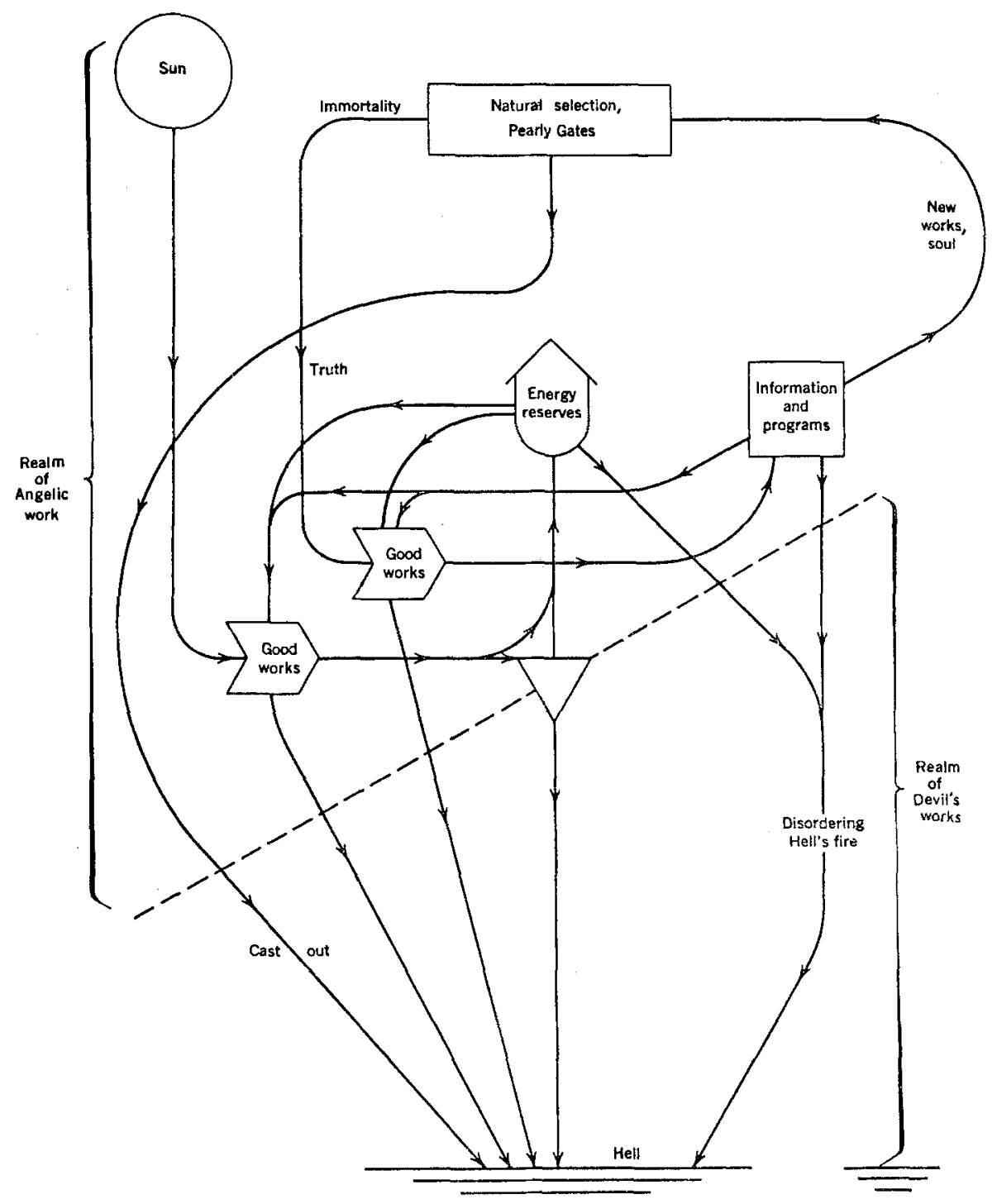

Fig. 1: Common abstractions of energetics and religious teachings showing angelic operations of order, evolution, and selection of information above, and the evil processes of disorder, dissipation, and heat death below (from Odum, 1971). [Faith seems to have been left out of this model, although the orthodox view is that salvation cannot be attained by good works alone. A strong element of Manichaean dualism is also built into the model]

phenomena of the natural or "real" world, have an inherent distrust of administration by simple differential equations and ad hoc rules based on simplified numbers. One need only remember the $\mathrm{pH}$ craze of a generation ago, when for a while it was thought this one value might answer all possible questions about the environment. It is fortunate that we did not have environmental agencies in those days, or we might now be 
running around madly with litmus paper and $\mathrm{pH}$ meters, adjusting all our activities to this single variable.

The late John Strickland was skeptical of the value of models to explain plankton dynamics, except the modelling of laboratory experiments, and obviously did not feel that the time had come for models of the plankton dynamics of the open sea. His final, grudging remarks express this reservation (Strickland, 1972):

"Such model-making is fun and there is perhaps now enough real information available that one feels all efforts are not in vain and predictive outputs have some value in showing the effect of changing various inputs or changing assumptions and formulae for various key processes. One can play God, by calling forth a theoretical sea where specified species of phytoplankton grow and are fed upon by specified species of predators. One then turns loose the computer and makes it predict the state of the universe in a given number of weeks.

I am not sure this is really getting us anywhere but in all fairness we need more time to find out whether any computerized conclusions are forthcoming which could not have been established by intuition.

In the meantime this effort has clearly underlined the many places where our current ignorance is the greatest and where we must concentrate future work if the coming decade is going to produce sufficient new data for us to be able to construct population dynamics which will be of real value to the engineer and oceanographer trying to take practical steps to improve marine food production or to redress the ravages of pollution in our rivers, lakes, and seas. ${ }^{\text {" }}$

But one must proceed with care in the construction and operation of even simple deterministic models that may behave in ways which suggest natural phenomena; May \& Oster (1976) refer to this property "as the snake-in-the-mathematical-grass called "bifurcations'." A sequence of such bifurcations may resemble the cyclic behavior of some insect populations (May \& Oster, 1976; p. 585):

"The implications for ecological theory of these high-order periods and aperiodic orbits are most unsettling. It means that, from the modelling point of view, it may well be practically impossible to distinguish data that have been generated by a rather simple deterministic process either from true stochastic noise or from 'experimental error ${ }^{\text {' }}$ in sampling or measurements. The decision as to when sufficiently accurate data have been collected, and whether the data show purely stochastic or deterministic characteristics, may well have to rest with one's biological knowledge external to the experiment, since no discrimination . . can be given on the basis of the data alone."

Obviously, the old-fashioned naturalist is still not obsolescent; indeed, he may be more needed than ever in these days of number-happy computers.

Hardly anyone now mentions or refers to that milestone of ecology affectionately called "the great AEPPS" (Allee et al., 1949). This work has indeed become somewhat dated in these days of ecosystems, theories and, of course, models, but in the last respect the book did predict a future trend of ecology with the elaborate diagram on page 722 (Fig. 2), almost the last in the book. It is to be noted that it was called a diagram, not a model, but it is not greatly different in approach than, for example, Odum's model of the energy circuits of an estuarine system (Fig. 3) reproduced as the frontispiece in Nihoul et al. (1975). In both cases, the designer has attempted to 


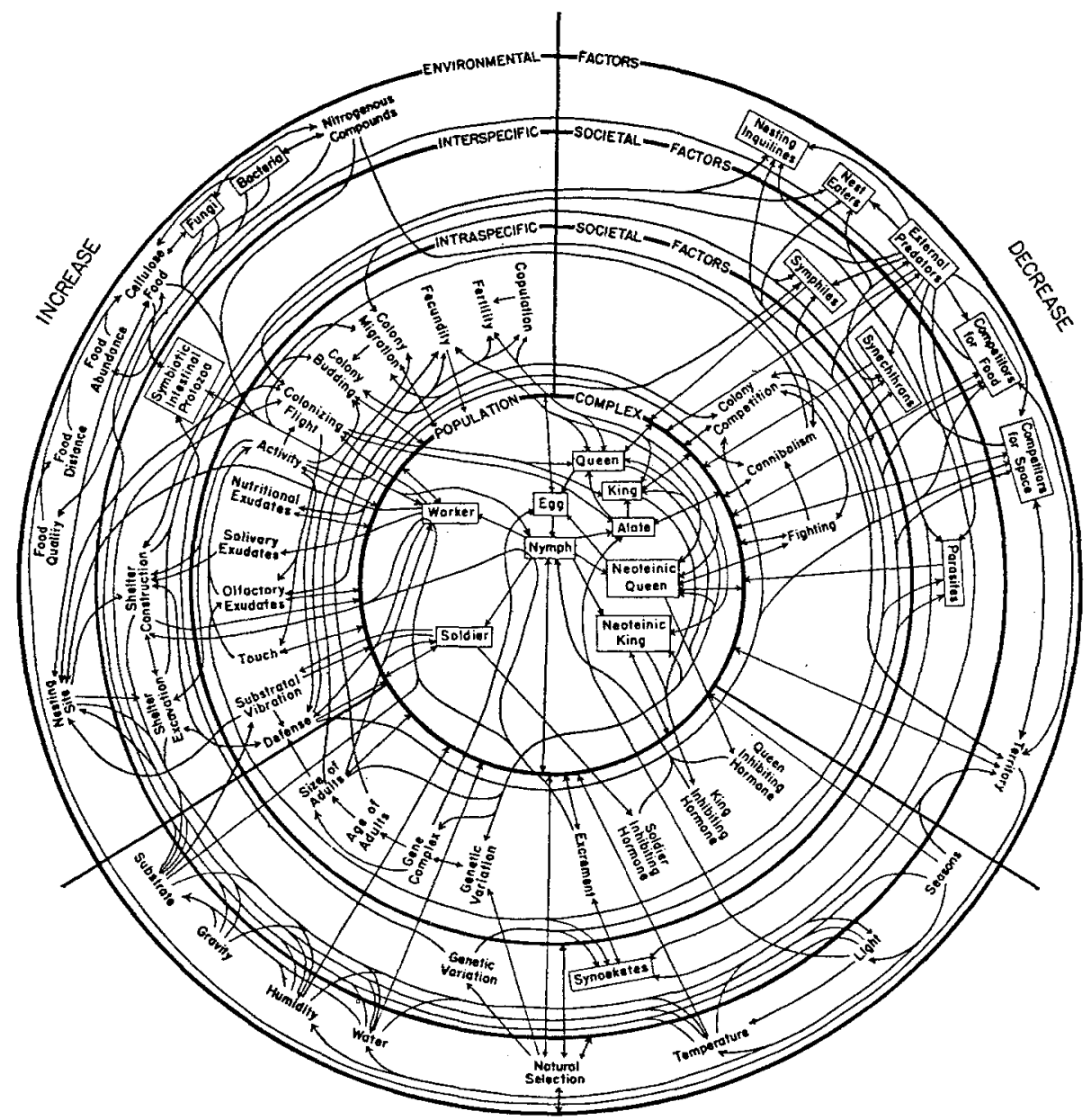

Fig. 2: Diagram of the factoral complex influencing the population of a typical termite of the family Rhinotermitidae. Arrows indicate the direction of the effect. (From Allee et al., 1949)

remember every possible interrelationship, reminding us by graphic means that the world of nature is indeed complicated.

To many people, numbers appear to be the essence of science that mathematicians claim them to be, and many administrators and officials of public hearing bodies, perhaps unwilling to admit they do not always follow equations easily, accept models drawn up in mathematical terms as realities beyond such mere facts of nature as the coming and going of the seasons, the birth and death and feeding of creatures, and their interactions with each other, which have all been bravely reduced to differential equations (subject to boundary conditions). It is easy to forget the model is an idealistic abstraction of the processes of nature, to be adjusted and revised when there is enough information for such "verification", and to conclude that the number that finally 


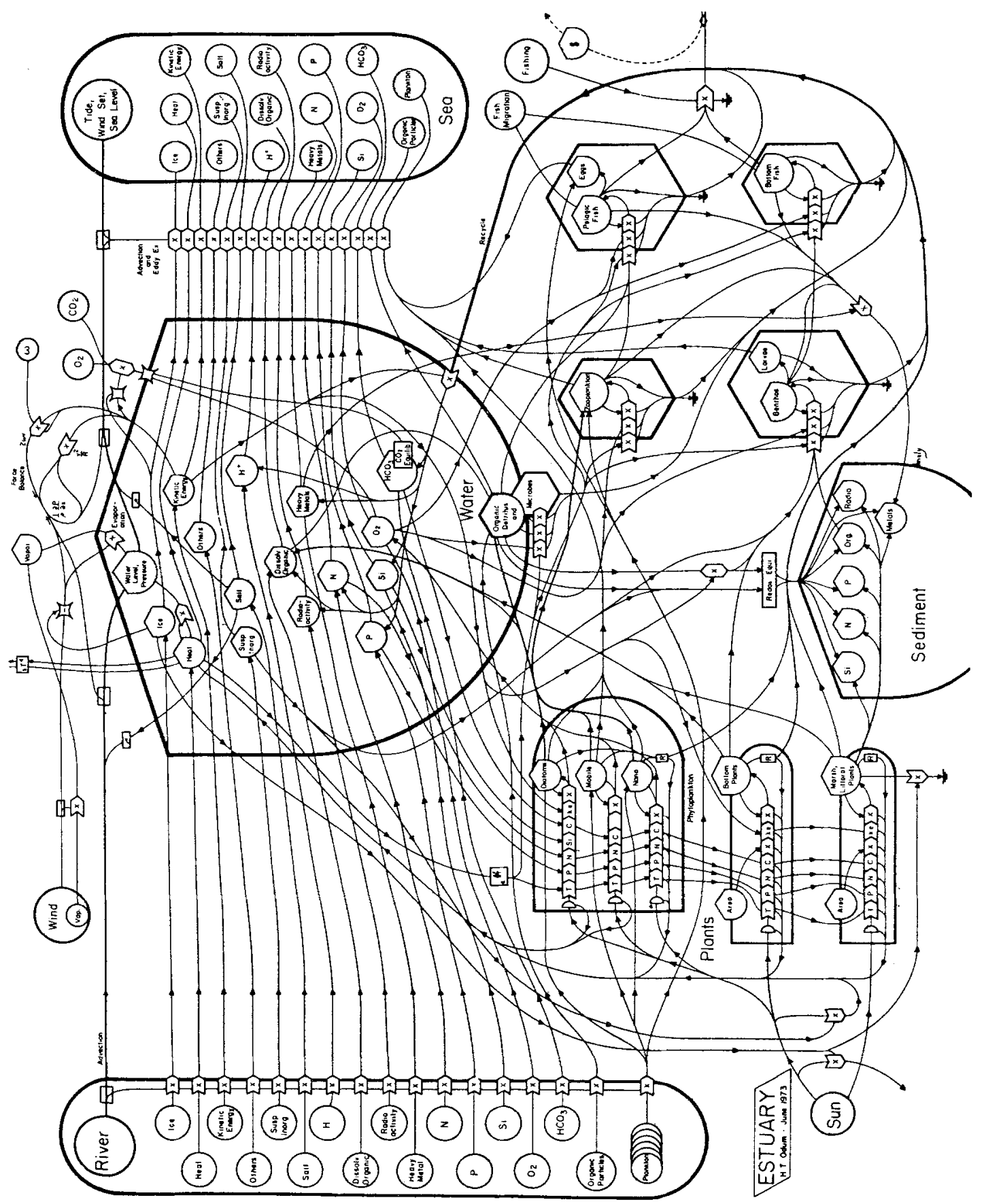

Fig. 3: Odum's model of an estuarine system transulated into energy circuit language. (From Nihoul et al., 1975, courtesy Elsevier Scientific Publishing Company and H. T. Odum who prepared this model so that the items of structure and process recommended as important in Marine Science studies by 5 subcommittees at the Portugal conference could be presented in an integrated manner rather than as 5 separate sciences) 
emerges from the computer has an intrinsic value that tells them whether the environment - and its organic life - is thriving, doing as well as can be expected (a medical euphemism for not getting any better), or is indeed in a bad way, and from this number they may make their management decisions.

Most of those involved in modelling and feeding their ideas into computers realize this, of course, and the recent literature concerning models (e.g., May, 1973 Steele, 1974; Nihoul et al., 1975) is full of cautions and reservations about the relations of models to reality, and their application to practical concerns.

We must not forget, of course, that marine ecology began with a model, a model or a theory developed almost within sight of Helgoland about a hundred years ago. This was the concept of the biocoenosis, based on observations of the oyster banks of Schleswig-Holstein by Karl Moebius. This original statement of the biocoenosis, published in "Die Auster und die Austernwirtschaft" (Moebius, 1877), was soon translated into English by the United States Fish Commission (Moebius, 1883), and remains today one of the most accessible, yet nevertheless unread, pioneer documents of marine ecology.

Karl Moebius was one of the great field zoologists of his time, if not of all times. $\mathrm{He}$ was a pioneer of fishery biology as well as a marine zoologist. He was the author of that well-known but now scarce classic, "Die Fauna der Kieler Bucht". Among his many accomplishments was an excellent monograph on the Pycnogonida of the Deutsche Tiefsee Expedition of the "Valdivia". In his earlier work on the oyster banks of Schleswig-Holstein and the North Sea, Moebius described the association of animals on the oyster banks of the North Sea, and from this study derived the concept of the biocoenosis (Moebius, 1883):

"Every oyster-bed is thus, to a certain degree, a community of living beings, a collection of species, and a massing of individuals, which find here everything necessary for their growth and continuance, such as suitable soil, sufficient food, the requisite percentage of salt, and a temperature favorable to their development. Each species which lives here is represented by the greatest number of individuals which can grow to maturity subject to the conditions which surround them, for among all species the number of individuals which arrive at maturity at each breeding period is much smaller than the number of germs produced at that time. The total number of mature individuals of all the species living together in any region is the sum of the survivors of all the germs which have been produced at all past breeding or brood periods; and this sum of matured germs represents a certain quantum of life which enters into a certain number of individuals, and which, as does all life, gains permanence by means of transmission. Science possesses, as yet, no word by which such a community of living beings may be designated; no word for a community where the sum of species and individuals, being mutually limited and selected under the average external conditions of life, have, by means of transmission, continued in possession of a certain definite territory. I propose the word Biocoenosis for such a community. Any change in any of the relative factors of a biocönose produces changes in other factors of the same. If, at any time, one of the external conditions of life should deviate for a long time form its ordinary mean, the entire biocönose, or community, would be transformed. It would also be transformed, if the number of individuals of a particular 
species increased or diminished through the instrumentality of man, or if one species entirely disappeared from, or a new species entered into, the community."

The idea of self-regulation governed by external conditions was, however, an idealistic box. The model conceived by Moebius was essentially a closed system. We now know that most ecological systems, especially those of the sea, are open systems, in balance with external conditions and much more adjustable to conditions than the original model of the biocoenosis. This was realized almost at the outset by Bashford Dean, the first critic of the concept of the biocoenosis (Dean, 1893):

"Moebius maintains that the size of the banks in a given region cannot be materially augmented - a matter which is of great interest even from the standpoint of pure biology. Not that it is at all to be questioned that a natural bank would under normal conditions remain more or less uniform in size and in the proportion of its component organisms - but it is the theory involved in this question that seems to the writer susceptible of broader interpretation than has been assigned it. Biocoenosis is the term applied by Moebius to express the mutual interdependence of species existing in a colony - a condition of happy-family existence in a natural cage whose limited food supply locks up the chances of permanent numerical increase. In accordance with this keenly poised life-balance, Moebius infers that the banks of the Wattenmeer can not be permanently added to, even by artificial means ("Auster und Austernwirtschaft", p. 78). He notes, for example, that a season favorable to oysters will, per se, cause the oysters during the following season to fall back to their normal, inasmuch as food material has thus been prepared for the enemies (crab and starfish) whose increased progeny will restore the balance of life.

The important inferences drawn from this doctrine of lifebalance do not, however, seem to be entirely warranted by the premises. We are led, for example, to infer that individuals are dependent upon the colony, and that the colony holds the curb, checking the permanent increase of one form at the expense of another. On the other hand, struggle for survival is undoubtedly the democracy of animal living, and in these days it has been pretty clearly established that the colony is but an incident more or less transient in the survival of the fittest. So the biocoenose, as we must accordingly admit, becomes but an episode in colonial life, whose duration depends upon the enduring force of its component species, where quickly moving predatory forms have the right of might, where stationary and defenseless forms have become mimics to escape their enemies, or have developed a surprising fecundity to survive the dangers of a compressed living-area or unfavorable environment. It can not at present be doubted that the scale of the struggle may readily be turned in favor of but a single type or species. Artificial devices may thus become the rapid undoing of the slowly struggling biocoenose, for they favor the protected species and would not unreasonably tend to blot out the accompanying enemis of this form."

In these excerpts, we have the gist of the modelling problem, stated clearly at the outset. Moebius saw the world of the oyster bank as an immutable or closed system, controlled by its own resources and internal dynamics. Bashford Dean saw the implication of this for management or improvement of oyster grounds. An open system could be manipulated, but a closed system as suggested by Moebius could not. In essence, while Moebius' model of the biocoenosis was an intuitive inspiration, some 
of his details were a muddle and to proceed upon them for the management of the oyster beds would have been unsuccessful. Practical oystermen, however, have never been interested in theory, and paid no attention to the biocoenosis, in any event.

To this day, of course, ecologists are not unanimous about models. In the same issue of the American Naturalist, Rothstein (1973) examined the model of nichevariation and found it "virtually impossible to invalidate", at least insofar as observations on birds were concerned, and Dayton (1973), on the basis of observations in the intertidal zone, found that while the predictions of similar models of resource partitioning were verified, "insights into the natural history and simple experimental manipulations demonstrated that a quite different mechanistic interpretation is correct."

The dangers of applying inappropriate models, or oversimplifying nature in testing models are implicit in Dayton's concluding remarks:

“... While ecological investigations of some situations may best be approached through the use of hypothetical models, my purpose here is (1) to demonstrate that blind application of such models may lead to serious interpretive errors even in a relatively simple community such as the intertidal, and (2) to emphasize the innate deviousness of ecological interactions. I suggest that, as the complexity of the system increases, overly simplistic models such as those based entirely on competition or on variants of the Lotka-Volterra equations are likely to be wrong with a frequency increasing as the number of complex interactions increases. ... I do not mean to deny the validity of the powerful hypothetico-deductive technique. In these examples I have demonstrated primarily that the premises of the models applied were not justified. ... The use of such models in complex situations seems appealing because they are thought to offer important shortcuts to correct generalizations; but it is clear that the models must be based on a thorough understanding of the relevant natural history, and, when possible, on some form of controlled manipulation. Once sufficient information is available to protect against the possibility of making the right prediction for the wrong reason, there often may be enough knowledge of the 'organization' of the community so that it is an open question whether the use of some models really does offer any shortcuts to correct generalizations."

Now, however, we have a growing class of individuals perhaps best categorized as ecological engineers who are unaware of these ecological refinements, or do not have time to read actively in the field in which they have become practitioners. Some of them are ecologists, or at least have been exposed to the word in a class or two in college, others are engineers of diverse backgrounds. Unfortunately, many of these poeple lack such perception as Bashford Dean obviously had, or appreciate Dayton's skill as a field observer, and often accept the latest interesting idea as the basis for their interpretation of the needs of society, or, more often than not, of the consulting agency that employs them. These people, along with attorneys of diverse backgrounds and interests, are becoming an influential force in the growing world of ecological or environmental politics. It is all too easy to misread ecological literature, and it is disconcerting, for example, to hear an obviously experimental exercize in modelling the Ross Sea plankton system interpreted as a substantial, factual document on the 
actual events and conditions in the Antarctic. The model itself is considered an excellent effort; the muddle comes from assuming it is a factual rather than theoretical contribution.

Although we now consider such statements as "survival of the fittest" somewhat old-fashioned, the basic argument advanced by Dean that the natural state of affairs, the biocoenosis or natural community in its setting, is more of an open than a closed system, is a surprisingly up-to-date point of view, and most of his remarks are surprisingly in harmony with those who look carefully at today's elaborate models of the natural environment.

It is perhaps significant that the old term "biocoenosis" seems to be giving way to "ecosystem", in agreement with the modern tendency of ecology to deal more with factors and interactions rather than stable communities and static descriptive terminology. One of the results of these speculations about interrelations and the dynamic nature of communities was the idea that the diversity of organisms in a given kind of environment, or the complexity of the natural system, was somehow related to stability or at least very slow change, and that such stability was somehow related to the evolutionary success of the community. It was an interesting idea, and a large literature has grown up around it, much as mushrooms spring forth after a rain in the woods, but, like so many other models, it was perhaps too eagerly accepted and produced a theory without the rigid structure required for a plant to survive more than a season. This has, for the most part, been reviewed by Goodman (1975), who presents an interesting story of how a plausible if unsubstantiated idea may be expanded to a theoretical structure, supported by interesting equations, yet turn out to be another interesting but unprovable theory.

When this idea of diversity as an index of stability appeared to be the latest addition to the ecological canon, the idea was accepted by sanitary engineers, who apparently inferred that "stability" was somehow synonymous with "health" and that

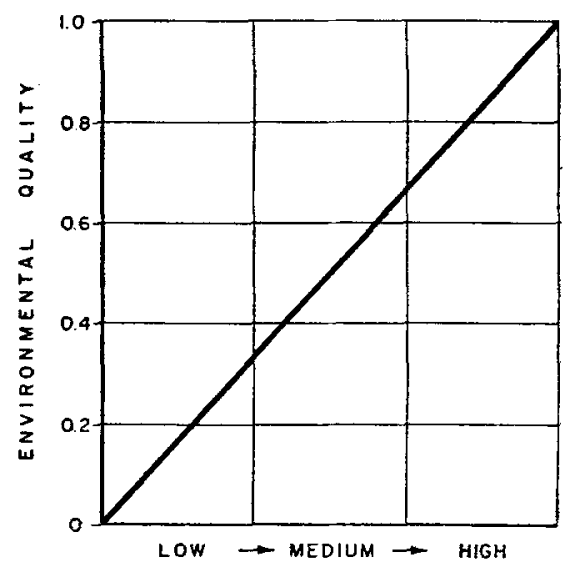

Fig. 4: A diagram to illustrate the relationship between mood/atmosphere and environmental quality (Dee et al., 1972). According to the text, such values as the feeling of "oneness with nature" may be derived from the position of this reaction - or emotion - on this arbitrary slope 


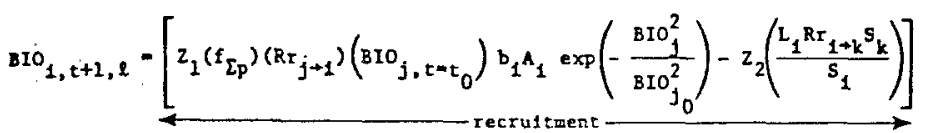

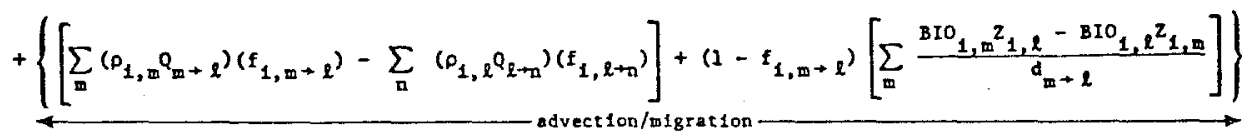

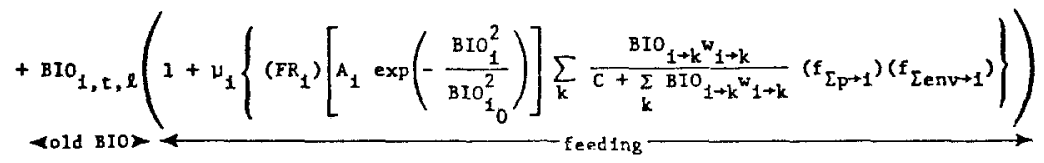

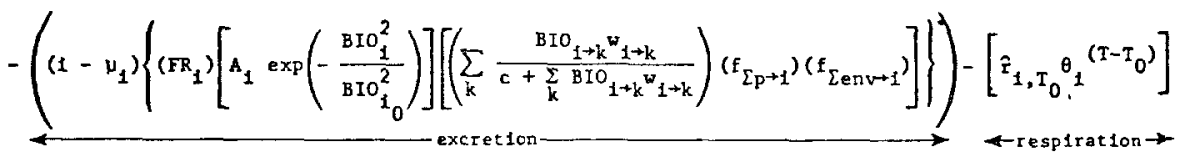

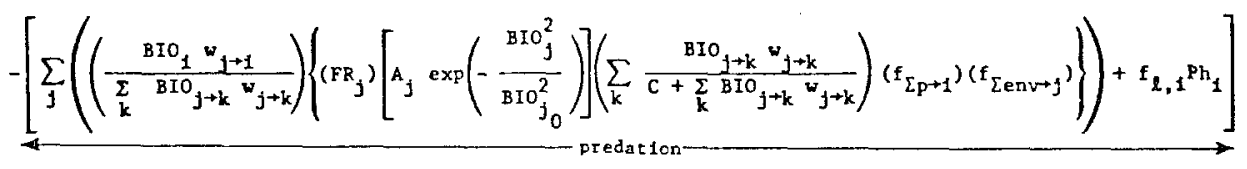

$$
\underbrace{-\left(a_{1}\left\{1+\prod_{1} A_{P_{j+1}} \exp \left[-\frac{\left(C_{P_{\max +1}}-C_{P_{1}}\right)^{2}}{\left(C_{P_{\max +1}}-C_{P_{1}}\right)^{2}}\right]+A_{F_{1}} \exp \left(-\frac{F_{1}^{2}}{F_{1_{0}}^{2}}\right)+A_{T_{1}} \exp \left[-\frac{\left(T_{1,0 p t}-T\right)^{2}}{\left(T_{1,0 p t}-I_{1}\right)^{2}}\right]\right\}\right)}
$$

where $z_{1,2}$ is defined as

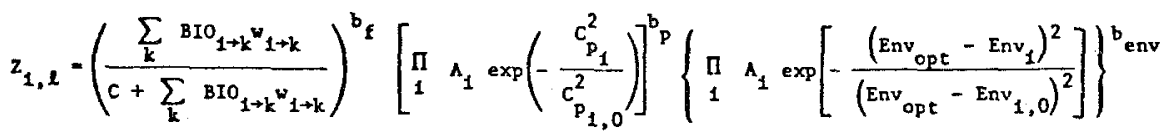

Fig. 5: A complete biomass equation, together with some of the criteria demanded by the model (Haven, 1975). The text goes on to suggest various compromises with reality that may be made to operate the model on an interim basis: "Ecological Model Data Requirements. It is readily apparent that operation of either of the proposed ecological models requires an extensive data base. More specifically, both the $\mathrm{I} / \mathrm{O}$ and the dynamic model require identification of the following: All food-web links; all link $\mathrm{w}_{\mathrm{j} \rightarrow \mathrm{k}}$ values; specific feeding rates and conversion rates $\left(\mu_{i}\right)$ for all taxa; pollutant-uptake rates for all potential pollutants by all taxa; pollutant effects (by concentration) to include lethal, sublethal, behavioral, and physical; human harvest rates; environmental tolerances and preferences by taxa. Moreover, the dynamic model will also require: Taxa half-saturation constants by pollutant and environmental parameter; reproductive and recruitment rates, times, controlling factors, etc.; advection or migration choice factors. In addition to this list of specific relationships, the dynamic model contains a number of constants that must be specified through parametrization techniques for data fitting. This process, of course, requires multiple data points for each parameter. Obviously many of these data are currently nonexistent. Thus fully determinant explicit operation of the models is not yet feasible" 
therefore a higher index of diversity indicated favorable conditions, or at least no deleterious effect of pollutants (Pearson et al., 1967).

Unfortunately, in this age of massive computers and eager young men, ideas and supporting data may be generated much more rapidly than most of us can keep up with, especially those not intimately involved in the mainstream of theory and action in ecology. The result is that erroneous ideas may have a longer half-life than correct ideas, and the idea that diversity may be an index of health, resistance to pollution, or whatever, seems to be one of the muddles that has persisted from what was for a time a stimulating model of ecology. Bureaucracies are notoriously resistant to change, and once a concept or principle has become accepted by bureaucrats, it may persist and affect policy long after it has been passed by in the "real world". The current obsession with modelling presents this danger to a high degree because the numbers look real, even when they may involve arbitrary readings from a $45^{\circ}$ slope expressing our feeling of mood-atmosphere or "one-ness with nature" (Dee et al., 1972), as suggested in Figure 4.

Models are a useful way of looking at nature, but mere skill with equations and diagrams is not necessarily related to biological sophistication or the existing data base, and much of the work with verifying and refining models involves reconciling their assumptions and abstractions with the "realities of the natural world" they were supposed to represent in the first place. It is all too easy for one adept with equations to produce a comprehensive model that seems to include, tell, and perhaps predict all, yet to find that all we need to know to apply the model is practically everything, and that most of this information is yet to be obtained (Fig. 5). Obviously there must be some simplification of this idealized algebraic summary of an ecology text, and according to the author "The limiting criteria tentatively planned for this simplification process are as follows: (1) All included species must occupy a similar position within the local food web (same sources, same predators). (2) All included species must display similar or complementary spatial or temporal distribution. (3) All included species must demonstrate similar uptake characteristics for all toxins modeled from each toxin source (food, water column, sediments). (4) Each taxon must represent a significant element within the bay ecosystem " (Haven, 1975).

These suggested criteria call for a theoretically and ecologically impossible suite of organisms. Since such combinations of organisms do not exist in nature, a selection assumed to meet these criteria would invalidate the operation of the model.

Obviously, the problem here is trying to do too much too soon. Models have been successful in fisheries management, where the emphasis has been in the population structure and environmental perturbations involving a single, or few species of fish (e.g., Cushing \& Walsh, 1976). The recent effort to construct comprehensive ecosystem models, however, does pose dangers, in the light of our inadequate knowledge (or incomplete "data base", which is the same thing), especially to funding for field studies and the advance of the needed knowledge to understand and administer the complex problems of the sea. There is, of course, no defense against misunderstanding of what is otherwise plain to everyone else, as Schiller said so long ago: "Mit der Dummheit kämpfen Götter selbst vergebens." 


\section{LITERATURE CIT'ED}

Allee, W. C., Emerson, A. E., Park, O., Park, T. \& Schmidr, K. P., 1949. Principles of animal ecology. Saunders, Philadelphia, 837 pp.

Cushing, D. H. \& Walsh, J. J. (Eds.), 1976. The ecology of the seas. Blackwell, Oxford, $467 \mathrm{pp}$.

Dayton, P. K., 1973. Two cases of resource partitioning in an intertidal community: making the right prediction for the wrong reason. Am. Nat. 107, 662-670.

Dean, B., 1893. Report on the European methods of oyster-culture. Bull. U.S. Fish Comm. 11, 357-406.

Dee, N., Baker, J. K., Drobny, N. L., Duke, K. M. \& Fahringer, D. C., 1972. Environmental evaluation system for water resource planning Final Rep. Batelle Columbus Lab. Contract 14-06-D-7812 (NITS PB-208 822), 189 pp.

Goodman, D., 1975. The theory of diversity-stability relationships in ecology. Rev. Biol. 50, 237-266.

Haven, K. F., 1975. A methodology for impact assessment in the estuarine/marine environment. Rep. Lawrence Livermore Laboratory, University of California (UCRL-51949), $43 \mathrm{pp}$.

Hedgpeth, J. W., 1957. Concepts of marine ecology. In: Treatise on marine ecology and paleoecology. Ed. by J. W. Hedgpeth. Geol. Soc. Am., New York, 1, 29-52. (Mem. geol. Soc. Am. 67.)

- - 1973. The impact of impact studies. Helgoländer wiss. Meeresunters. 24, 436-445.

May, R. M., 1973. Stability and complexity in model ecosystems. Princeton University Press, Princeton, N. J., 235 pp.

- \& Oster, G. F., 1976. Bifurcations and dynamics complexity in simple ecological models. Am. Nat. 110, 573-599.

Moebius, K., 1883. The oyster and oyster-culture. Rep. U.S. Commnr Fish., 1880, 683-751.

Nihoul, J. C. J. (Ed.), 1975. Modelling of marine systems. Elsevier, Amsterdam, 272 pp.

Odum, H. T., 1971. Environment, power and society. Wiley-Interscience, New York, 331 pp.

Pearson, E. A., Storrs, P. N. \& Selleck, R. E., 1967. Some physical parameters and their significance in marine waste disposal. In: Pollution and marine ecology. Ed. by T. A. Olson \& F. J. Burgess. Wiley-Interscience, New York, 297-315.

Rothstein, S. I., 1973. The niche-variation model - is it valid? Am. Nat. 107, 589-620.

Steele, J. H., 1974. The structure of marine ecosystems. Blackwell, Oxford, 128 pp.

Strickland, J. D. H., 1972. Research on the marine planktonic food web at the Institute of Marine Resources: A review of the past seven years of work. Oceanogr. mar. Biol. 10, 349-414.

Author's address: Dr. J. W. Hedgpeth

5660 Montecito Avenue

Santa Rosa, California 95404

USA 